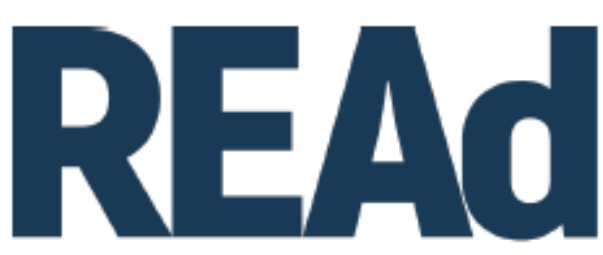

Revista Eletrônica de Administração

\title{
GLOBALIZAÇÃO, (DE)COLONIALIDADE E (CONTRA)HEGEMONIA NO CONTEXTO DA INTERNACIONALIZAÇÃO DA EDUCAÇÃO SUPERIOR: O GRITO SURDO DA ACADEMIA ${ }^{1}$
}

\author{
Mário César Barreto Moraes ${ }^{2}$ \\ Fernanda Geremias Leal ${ }^{3}$
}

$\underline{\text { http://dx.doi.org/10.1590/1413-2311.316.103166 }}$

\begin{abstract}
RESUMO
O objetivo deste ensaio teórico é propor uma análise crítica e reflexiva do fenômeno da internacionalização da educação superior, a partir de conceitos estruturantes associados a globalização, (contra)hegemonia e (de)colonialidade. Os seguintes argumentos estruturam o texto: 1. Sendo a educação superior um campo relacional de poder, composto de redes e relacionamentos concomitantemente competitivos e cooperativos e permeado por influências econômicas vinculantes, a internacionalização da educação superior se ressente de uma delimitação que efetivamente a contextualize; 2. As desigualdades subjacentes às relações Norte-Sul se manifestam no domínio da internacionalização da educação superior, incluindo nas relações Sul-Sul, e ratificam o exercício do poder relacional e econômico; e 3. O fenômeno da internacionalização da educação superior encontra-se ontológica e epistemologicamente imerso na matriz cultural do poder colonial e atua sob o alicerce de um imaginário global dominante. O estudo possibilita evidenciar que os referenciais teóricos tendem a conceber os conceitos inerentes a globalização, (contra)hegemonia e (de)colonialidade de forma dicotômica, sem considerar a realidade híbrida, conflitante e complexa da educação superior e da internacionalização.
\end{abstract}

Palavras-chave: Educação Superior. Internacionalização. Globalização. Hegemonia. Colonialidade.

\section{GLOBALIZATION, (DE)COLONIALITY AND (COUNTER)HEGEMONY IN THE CONTEXT OF INTERNACIONALIZATION OF HIGHER EDUCATION: THE DEAF CRY OF THE ACADEMIA}

The objective of this theoretical essay is to propose a critical and reflective analysis of the phenomenon of the internationalization of higher education, based on structural concepts

\footnotetext{
${ }^{1}$ Recebido em 19/5/2020, aceito em 22/6/2021.

2 Universidade do Estado de Santa Catarina - Escola Superior de Administração e Gerência; Florianópolis (SC), Brasil; http://orcid.org/0000-0002-0760-8444; mcbmstrategos@ gmail.com.

${ }^{3}$ Universidade Federal de Santa Catarina - Pró-Reitoria de Desenvolvimento e Gestão de Pessoas; Florianópolis (SC), Brasil; http://orcid.org/0000-0002-1716-2060; fernanda.leal@ufsc.br.
} 
associated with globalization, (counter)hegemony and (de)coloniality. The following arguments structure the text: 1 . Since higher education is a relational field of power, composed of concomitantly competitive and cooperative networks and relationships, and permeated by binding economic influences, internationalization of higher education resents a delimitation that effectively contextualizes it; 2 . Inequalities underlying North-South relations manifest in the field of internationalization of higher education, including in South-South relations, and ratify the exercise of relational and economic power; and 3. The internationalization phenomenon of higher education is ontological and epistemologically immersed in the cultural matrix of colonial power and operates under the foundation of a dominant global imaginary. The study suggests that theoretical references tend to conceive the concepts inherent to globalization, (counter)hegemony and (de)coloniality in a dichotomous way, without considering the hybrid, conflicting and complex reality of higher education and internationalization.

Keywords: Higher Education. Internationalization. Globalization. Hegemony. Coloniality.

\section{GLOBALIZACIÓN, (DE)COLONIALIDAD Y (CONTRA)HEGEMONÍA EN EL CONTEXTO DE LA INTERNACIONALIZACIÓN DE LA EDUCACIÓN SUPERIOR: EL GRITO SORDO DE LA ACADEMIA}

El objetivo de este ensayo teórico es proponer un análisis crítico y reflexivo del fenómeno de la internacionalización de la educación superior, a partir de conceptos estructurales asociados a globalización, (contra)hegemonía y (des)colonialidad. Los siguientes argumentos estructuran el texto: 1. Dado que la educación superior es un campo de poder relacional, compuesto de redes y relaciones competitivas y cooperativas concomitantemente y permeado por influencias económicas vinculantes, la internacionalización de la educación superior resiente una delimitación que efectivamente la contextualiza; 2. Las desigualdades subyacentes a las relaciones Norte-Sur se manifiestan en el campo de la internacionalización de la educación superior, incluso en las relaciones Sur-Sur, y ratifican el ejercicio del poder relacional y económico; y 3. El fenómeno de la internacionalización de la educación superior es ontológica y epistemológicamente inmerso en la matriz cultural del poder colonial y opera bajo la base de un imaginario global dominante. El estudio sugiere que los referentes teóricos tienden a concebir los conceptos inherentes a la globalización, (contra)hegemonía y(des) colonialidad de manera dicotómica, sin considerar la realidad híbrida, conflictiva y compleja de la educación superior y la internacionalización.

Palabras clave: Educación Superior. Internacionalización. Globalización. Hegemonía. Colonialidad.

\section{INTRODUÇÃO}

A idealização de uma sociedade global sugere um exercício de cidadania análogo. Desse modo, expressões como cosmopolitanismo e cidadania global imputam uma mudança ao conceito de estado-nação. Em que pesem as noções de globalização e cosmopolitanismo remeterem à antiga Grécia, as redes que estão interligadas independentemente de quaisquer 
sociedades têm incrementado a noção de uma cidadania cosmopolita e globalizada (PHILLIPS, 2014).

O foco nessa perspectiva particular de cidadania se identifica como uma questão educacional imprescindível para lidar com as crescentes formas de globalização econômica, política e social (PHILLIPS, 2014). Tais efeitos se convergem sobre as instituições de educação superior de modo a ensejar um certo isomorfismo organizacional, na busca de uma perspectiva subjetiva de êxito (MOROSINI, 2006), vinculada a uma proposta de internacionalização.

A internacionalização tem sido gradativamente referenciada no contexto da educação superior como critério de qualidade e como recurso para que as universidades respondam às crises e aos desafios de um contexto global complexo, volátil e incerto (STEIN, 2017). No Brasil, a partir da década de 1990, mas sobretudo com os programas governamentais diretamente vinculados ao conceito - como Ciência sem Fronteiras (CsF) (2011-2015), Idiomas sem Fronteiras (IsF) (2012-Atual) e Programa Institucional de Internacionalização (CapesPrInt) - o tema ganhou a atenção das estruturas universitárias e, com a chancela de agênicas e organismos internacionais, passou a influenciar seus planejamentos estratégicos institucionais e governamentais (LEAL; MORAES, 2018; PROLO et al., 2019; LEAL, 2020; KNOBEL et al., 2020). Tais instituições estabelecem prescrições relacionadas à necessidade de reformas curriculares mais condizentes com as demandas globais e incorporam os conceitos de cidadania global e de competência intercultural como objetivos de formação (GOMES; ROBERTSON; DALE, 2012; LEASK; BEELEN; KAUNDA, 2013; LIMA; MARANHÃO, 2011; RIVZI, 2007).

Não obstante o foco atribuído à internacionalização pelas instituições de educação superior, não se vislumbra um consenso sobre o seu significado e tampouco existe, de forma explícita, um modelo padronizado para que as universidades ampliem suas dimensões internacional, global ou intercultural (KNIGHT, 2015). Além disso, as contradições e os dilemas associadas ao fenômeno, que impactam sobretudo os países com menos condições de capitalizar sobre a criação e o uso do conhecimento (LEAL; MORAES, 2018), induz a um quadro eivado de indefinições quanto ao papel, a função e o lugar do processo de internacionalização das universidades no mundo.

Trata-se de uma realidade que suscita questionamentos acerca dos verdadeiros beneficiários desse processo. Países do chamado Sul Global tendem a seguir "o comando ativo dos países centrais, fornecendo cérebros, recursos financeiros e comprando produtos educacionais ali produzidos" (LIMA; CONTEL, 2011, p. 16) e, com isso, se revelam como alvo fácil dos interesses externos que visam apenas ao enfoque econômico (LEAL; MORAES, 
2018).

Relembrando um fenômeno cuja denominação se deu em função dos atores, dos idiomas e das instituições que projetaram como universal sua própria visão de mundo (MIGNOLO; WALSH, 2018), o Eurocentrismo, pode-se inferir que as desigualdades subjacentes às relações Norte-Sul - cujas origens remetem aos padrões eurocentrados de poder impostos no período colonial (QUIJANO, 2005) - também se manifestam no domínio da educação superior.

Embora se possa interpretar o processo de internacionalização como um fenômeno ontologica e epistemologicamente imerso na matriz cultural do poder colonial, que tem por amálgama um imaginário global dominante e que depende de de desigualdade e hierarquia para que possa existir (LEAL, 2020), se reconhece que a educação superior compreende um campo relacional de poder, com fissuras, contradições e questionamentos à ordem hegemônica (MARGINSON; ORDORIKA, 2011; LEITE; GENRO, 2012). Assim, objetiva-se, neste artigo, propor uma análise crítica e reflexiva do fenômeno da internacionalização da educação superior, a partir de conceitos estruturantes associados a globalização, (contra)hegemonia e (de)colonialidade.

A expectativa é de que a reflexão proposta suscite o surgimento de pensamentos alternativos para os estudos em internacionalização da educação superior; que amplie o horizonte epistemológico para responder aos problemas estruturais evidenciados no campo e que contribua para o entendimento desse fenômeno social complexo, sobretudo no contexto dos países do Sul Global.

Após esta introdução, a estrutura do ensaio teórico obedece à seguinte lógica: Inicialmente, contextualizam-se a globalização, a colonialidade/decolonialidade a hegemonia/contra-hegemonia. Na sequência, abordam-se as dinâmicas e as contradições evidenciadas no campo da internacionalização da educação superior. O texto segue com a exploração dos dilemas, das contradições e da colonialidade imbricadas ao contexto da internacionalização, acompanhado do debate sobre as possibilidades de inserção da perspectiva contra-hegemônica/decolonial nos estudos sobre internacionalização, tendo como referência a natureza crítica e analítica dessa epistemologia e a sua relação às tendências eurocentradas da modernidade.

\section{A RACIONALIDADE OCULTA DA GLOBALIZAÇÃO}

A idealização de um mundo sem fronteiras, que carrega em seu bojo a noção de uma comunidade universalizada, insere uma proposta de cidadania global e reforça um princípio de 
cosmopolitismo, na qual se apresenta o "cidadão do mundo". Esse cidadão estaria inserido em uma sociedade interligada, interconectada e totalmente interdependente (PHILLIPS, 2014), que se traduziria em uma "sociedade globalizada".

É nesse contexto de avanços tecnológicos que Phillips (2014, p. 351, tradução nossa) instrumentaliza seu conceito de globalização: "Uma expressão, frequentemente utilizada para designar diferentes povos de um mundo cada vez mais econômica, política e culturalmente interdependente, [...] necessariamente unido por um comércio global”. De modo análogo, Sandroni (1999, p. 265) reforça a perspectiva e define como globalização como "o fim das economias nacionais e a integração cada vez maior dos mercados, dos meios de comunicação e dos transportes". Em resumo, globalização, para esses autores, é um fenômeno que enfatiza a circulação de bens, serviços, dinheiro, tecnologias, informações, conhecimentos, pessoas e culturas. Tal fenômeno teria emergido no fim da década de 1980 e trazido consequências sem precedents, como a redução da soberania dos Estados, da capacidade de resistir às regras do Mercado mundial e da possibilidade de autonomia cultural e de estabilidade identitária.

Para Wallerstein (2006), todavia, vive-se um momento de transformação não devido a uma globalização com regras claras recentemente impostas, uma vez que os processos inerentes à globalização remontam a mais de quinhentos anos. Fairclough (2012, p. 314) complementa que

o fenômeno largamente conhecido como globalização não é simplesmente um movimento das organizações e processos econômicos de uma escala essencialmente nacional para uma essencialmente global: a globalização tem uma longa história e o que de fato está em jogo são as novas relações entre as escalas.

Vieira, Vieira e Filomeno (2012, p. 10), em perspectiva semelhante, reforçam que mesmo se pensada em termos eventuais, a globalização não se trata de um fenômeno recente. Estaríamos, hoje, vivenciando uma quarta onda desse fenômeno:

\footnotetext{
A primeira ocorreu no século XIII e foi estudada por Janet L. Abu-Lughod no livro 'Before European Hegemony - The World System A.D. 1250-1350' (Oxford University Press, 1989); a segunda, iniciada pelos portugueses no século XV, deu lugar, já no século XVI, ao que se convencionou chamar Os Grandes Descobrimentos e ao nascimento da Economia-Mundo Capitalista; a terceira, no século XIX, liderada pela Grã-Bretanha, deu lugar ao que Hobsbawn chamou a era do Imperialismo e praticamente incorporou todo o globo terrestre à Economia-Mundo Capitalista.
}

Para Sousa Santos (2011, p. 53), a denominada globalização não se apresenta de modo consensual, mas como "um vasto e intenso campo de conflitos entre grupos sociais, Estados e interesses hegemônicos, por um lado, e grupos sociais, Estados e interesses subalternos, por outro". Nesse viés, om campo hegemônico é constituído dos Estados que compõem o núcleo 
do sistema mundial, que impoem determinadas características aos demais, relativas principalmente às políticas mundiais de desenvolvimento e ao papel do Estado na economia, legitimando-as como as únicas possíveis ou adequadas. Esse quadro, emoldurado como "desenvolvimento" suscita uma conveniente discricionariedade:

Tal desenvolvimento também contribui para que brilhe um colonialismo, que, para alguns, representa do lado negro da globalização. Por outro lado, a globalização cria e demanda por novas concepções de cidadania e também serve como desafio a educadores e filósofos da educação. (PHILLIPS, 2014, p. 351, tradução nossa).

Os países periféricos e semiperiféricos são aqueles para os quais as características dominantes da globalização foram e continuam sendo mais fortemente impostas, reforça Sousa Santos (2011), por meio, por exemplo, dos programas de ajustamento estrutural, criados e impostos pelas instituições financeiras multilaterais como condição para a renegociação de suas dívidas externas:

\footnotetext{
Se para alguns ela [a globalização] continua a ser considerada como o grande triunfo da racionalidade, da inovação e da liberdade, capaz de produzir progresso infinito e abundância ilimitada, para outros ela é anátema, já que no seu bojo transporta a miséria, a marginalização e a exclusão da grande maioria da população mundial, enquanto a retórica do progresso e da abundância se torna em realidade apenas para um clube cada vez mais pequeno de privilegiados (SOUSA SANTOS, 2011a, p. 53).
}

A globalização compreende, assim, um grande número de pessoas e países que, essencialmente procuram por duas possibilidades (PHILLIPS, 2014, p. 351, tradução nossa): “(1) a potencial dominação por grupos mais poderosos (tipicamente operando como extensão dos estados-nação) ou (2) a consistente perspectiva da cooperação, como ideal de uma comunidade ou sociedade global". Em termos de dominação, remete-se, invariavelmente, ao poderio naval europeu, exercido com ênfase nos séculos 16 e 17, a serviço da colonização de diversas regiões do mundo. Remete-se, também, ao exercício do poder militar e econômico dos Estados Unidos e na manutenção de seus interesses, como forma consistente de dominação e exercício de imperialismo.

Pode-se, ainda, fazer referência à dominação da antiga União Soviética, atual Rússia, em partes da Ásia e da Europa. Sob o olhar da colaboração, na busca de uma comunidade global, em que estados-nação procuram unir esforços para alcançar objetivos comuns, tem-se como exemplo a criação das Nações Unidas, que se propõe a promover a paz e segurança mundiais. Outros organismos internacionais avocam em seus discursos o propósito da cooperação: Organização para Cooperação e Desenvolvimento Econômico (OCDE), Fundo Monetário Internacional (FMI), Organização Mundial do Comércio (OMC), Banco Mundial (BM), entre outros. 
Entretanto, no caso de tais organismos, as críticas encontram eco ao se depararem com a existência de um poder econômico subliminar, sendo mais bem assimilados como veículos de dominação em vez de cooperação, inobstante os eventuais benefícios decorrentes das políticas que desenvolvem para minimizar as barreiras comerciais e o protecionismo a países ou indústrias específicas (PHILLIPS, 2014). Paradoxalmente, os organismos que, em tese, nasceram com o objetivo maior de promover a cooperação no contexto da sociedade globalizada, são os mesmos descritos como promotores da globalização neoliberal ou simplesmente 'neoliberais' e que atraem os maiores movimentos de oposição.

Nayar (2015, p. 85-86, tradução nossa) ratifica a posição de Phillips (2014) acerca da racionalidade associada à globalização, observando que para os estudos pós-coloniais, globalização é uma versão de imperialismo. Tal perspectiva se ratifica nas seguintes conotações:

Em primeiro lugar, [globalização] significa, simplesmente a circulação de mercadorias [...] do primeiro mundo [...] em países do terceiro mundo. Em segundo lugar, globalização é a continuação da exploração das condições de trabalho [...]; Terceiro, implica em grave forma de imperialismo cultural, no qual as culturas locais são lentamente apagadas em favor dos produtos do Primeiro Mundo; Quarto, o primeiro mundo e as corporações transnacionais exploram os recursos naturais das nações do Terceiro Mundo como uma extensão das práticas mais antigas do colonialismo; Quinto, as políticas econômicas, políticas e mesmo sociais das nações são determinadas por tratados, injunções e decisões e ameaças veladas de fora para dentro do país. Ou seja, as economias nacionais individuais estão sujeitas a mudanças no sistema e na política econômica global. Finalmente, a globalização para as nações pós-coloniais é visa como um enfraquecimento de seus projetos de descolonização.

Esse modelo de sociedade, para Nayar (2015), não respeita fronteiras nacionais, mas as elimina, reforçando a noção de globalização como antítese de descolonização e a definindo como uma extensão do colonialismo, em um evidente desenho de neocolonização. O exposto é endossado por vias dominação cultural, segundo uma perspectiva de homogenização das sociedades (PHILLIPS, 2014), que se manifesta globalmente, com a disseminação de produtos e alimentos, moda e entretenimento, que são assimilados e resignificados nas culturas locais.

Hobson, em 1902, traz uma interpretação do início do século passado que se confunde com a propria globalização:

Um processo social parasitário, através do qual interesses econômicos existentes no interior do Estado, usurpando rédeas do governo, promovem a expansão imperialista para explorar economicamente outros povos, de modo a extorquir-lhes a riqueza para alimentar o luxo nacional (HUNT, 1995, p. 583).

Para Honderich (1995), o conceito de imperialismo é muito abrangente, compreendendo a opressão ou exploração da fraqueza ou pobreza de alguns países, pelos poderosos, porém muitos intelectuais entendem que o termo sugere um tipo de aprovação. São diversas as 
explicações sobre imperialismo, sendo que muitas se sustentam em teorias específicas, como a teoria da dependência de Lenin. Para Landes (1988), algumas características são inerentes ao imperialismo e, em maior ou menor grau, se confundem com a própria globalização, destacando-se duas:

(a) O principal objetivo do imperialismo foi extrair riqueza e mão-de-obra, mais do que estava disponível a um preço de mercado livre [...]; e (b) quase todos os imperialismos proporcionam sofrimento material e psicológico ao povo subjugado; mas também ganhos materiais diretos e indiretos, pretendidos ou não [...]. (LANDES, 1998, p. 488).

Landes (1988, p. 490) resgata duas teses, uma com posição favorável e outra contrária ao imperialismo na sua relação com o colonialismo, argumentando:

\begin{abstract}
Tentemos contrapor teses em função dos fatos: As nações economicamente atrasadas teriam crescido e progredido (no sentido de técnica e produtividade) mais depressa se nunca tivessem conhecido o colonialismo. A tese pró assenta numa hipótese: No pressuposto que esses povos subjugados teriam permanecido livres da exploração tanto interna quanto externa; seriam, além disso, capazes de aprender e mudar. A tese contra apoia-se na história: O imperialismo nunca impediu que algumas colônias se desenvolvessem como centros autônomos, nem que aprendessem e inventassem as técnicas de uma economia industrial.
\end{abstract}

Inobstante as motivações imperialistas, Nayar (2015, p. 41, tradução nossa) reconhece que há "outras formas de imperialismo, como o cultural e o linguístico, que ganharam atenção com os estudos pós-coloniais, especialmente a partir dos anos 1990”. Seu rastro abrange a defesa de um idioma comum, bem como uma linguagem comercial universal. Nayar (2015, p. 41, tradução nossa) observa ainda que, de padrões estéticos a modelos de organização e de espaços de trabalho, um imperialismo cultural busca assegurar certa homogeneização que, no específico, substitui formas culturais locais:

No caso do imperialismo cultural, não se trata de exploração econômica dos sujeitos locais, mas de uma desvalorização das tradições nativas, procurando afastar os jovens dessas tradições. O imperialismo cultural trabalha pela hegemonia, valendo-se do consentimento e não da força ou da coerção.

A globalização, portanto, traz consigo uma transformação, ao tempo em que se refere a um processo de apropriação, pelas diferentes comunidades, das evoluções mundiais. Nesse sentido:

A globalização afeta cada país de uma diferente forma de acordo com a história da nação, tradições, cultura e prioridades; globalização tende a considerar a sociedade como um todo e a ignorar a existência de nações e sua diversidade e se direciona mais para similaridades do que para diferenças. (MOROSINI et al., 2006, p. 95).

No domínio político, reforça Ramos (1995, p. 60) que "uma interpretação globalista é um instrumento de potenciação daquelas tendências, enquanto de um lado, racionaliza um 
processo societário global, de outro, contribui para minar os fundamentos psicológicos e sociais dos grupos que opõem obstáculos a este processo". Em 1848, Marx e Engels já destacavam o caráter cosmopolita dado à produção e ao consumo em todos os países, com matérias-primas originárias das regiões mais distantes para gerar produtos consumidos em todas as partes do globo, retirando da indústria sua pretensa base nacional. Antecipavam, com isso, a definição de globalização, observando que esta, em substituição ao "antigo isolamento de regiões e nações que antes se bastavam a si próprias, desenvolve um intercâmbio universal, uma universal interdependência das nações. E isto se refere tanto à produção material como à produção intellectual" (MARX; ENGELS, 1951, p. 8).

Para Hobsbawn (1995, p. 172), “o antiimperialismo e os movimentos de libertação coloniais se inclinaram em sua maioria para a esquerda. O motivo fundamental é que a esquerda ocidental era o viveiro das teorias e políticas antimperialistas, e o apoio aos movimentos de libertação colonial vinha em maior parte da esquerda internacional”. De modo análogo, dinâmica da 'globalização' e os movimentos inerentes à 'antiglobalização' a partir dos anos 1990 passaram a proliferar globalmente, de várias formas, mas derivadas das teorias neomarxistas, conforme reforça Kellner (apud CURREN, 2003, p.171, tradução nossa):

\footnotetext{
Ao longo da proliferação das teorias neomarxistas de cultura, sociedade e globalização de estudos culturais, viu-se emergir uma pedagogia crítica que se opõe explicitamente ao modelo de escolarização nas sociedades capitalistas, enquanto clama por maior emancipação do modelo educacional.
}

Esse modelo de escolarização deveria incorporar 'valores educacionais globais', como propõe Zajda (2009), que passam a traduzir padrões de 'excelência' e de 'qualidade' desejáveis ao desenvolvimento das sociedades globalizadas. Esses valores educacionais (ZAJDA, 2009; PHILLIPS, 2014) abrangeriamum grande senso de comunidade, com ênfase na diversidade cultural, tanto quanto um profundo entendimento crítico de democracia, igualdade, direitos humanos e justiça social. Como contraponto, a ideologia neoliberal na educação seria caracterizada por uma inexorável busca obsessiva por desempenho acadêmico, embasado em padrões globais de excelência, em avaliação acadêmica global e em rankings internacionais de performance institucional (PURPEL, 1999; ZAJDA, 2009; PHILLIPS, 2014), sendo que abordagens que explicitem uma possível cumplicidade entre os 'valores educacionais globais' e o projeto neoliberal na educação superior são raras.

\section{O SILÊNCIO COLONIAL DA MODERNIDADE}


Segundo Leal, Moraes e Oregioni (2018, p. 114) "a racionalidade específica da globalização dificilmente poderia ser compreendida sem uma familiarização com o padrão de poder estabelecido na América durante o período colonial”. Para Quijano (2005) são duas bases que fundamentam esse padrão de poder: (I) a ideia de raça, utilizada para diferenciar colonizadores de colonizados e legitimar a associação de suas respectivas identidades a hierarquias, lugares e papeis sociais e (II) todas as formas históricas de controle e de exploração do trabalho, seus recursos e produtos, em torno do capital e do mercado mundial.

Esse padrão de poder vai fundamentar o capitalismo mundial como estrutura hegemônica das relações de produção e pavimentar o desenvolvimento e a superioridade da perspectiva eurocêntrica do conhecimento. As colonias derivadas do exercício desse padrão de poder exercido são posicionadas em situação natural de inferioridade, tanto quanto suas descobertas mentais e culturais (QUIJANO, 2005; STEIN, 2017; LEAL; MORAES; OREGIONI, 2018). É essa subvalorização ou desvalorização dos conhecimentos e das descobertas intelectuais dos povos subjugados pelo poder colonizador que evidencia a violência epistêmica:

\begin{abstract}
Cada era tem seu próprio modo de construção do conhecimento, que Foucault denomina como 'episteme', tendo a teórica pós-colonial Gayatri Spivak em seu ensaio "Can the Subaltern Speak?", de 1988, desenvolvido a ideia de "violência epistêmica". Spivak argumenta que toda produção de conhecimento tem sua própria forma de violência, especialmente quando este conhecimento é sobre colonização ou assuntos inerentes e produzido por uma colônia. Qualquer conhecimento produzido pelo Ocidente (pelos colonizadores), se torna verdade estabelecida, para ser consumida por ambos - colonizadores e nativos da colônia. A produção de conhecimento, ou epistemologia, está intimamente conectada à violência da colonização, à dominação e desapropriação dos assuntos nativos (NAYAR, 2015, p. 65, tradução nossa).
\end{abstract}

A violência epistêmica nos textos pós-coloniais, conforme Nayar (2015), joga tanto com a opressão quanto com a emancipação colonial, evidenciando-se formas dessa violência em colônias do Novo Mundo, ao ignorar sistematicamente o conhecimento e as percepções dos nativos. Phillips (2014) reitera a perspectiva pós-colonial, reiterando Spivak (1988), quando argumenta a respeito do constrangimento sofrido pela própria colônia, diante da imposição linguística pelo grupo dominante, impossibilitando a voz subalterna ser ouvida. É na coerção desse silêncio que se subestima o escopo repressivo da hegemonia colonial: "seu lado destrutivo e genocida" (DUSSEL, 1993, p. 75, tradução nossa) em relação a outras epistemes que não a sua própria.

O termo colônia, tem origem no Latim, significando "para cultivo" e remonta ao Império Romano, que colonizou grande parte do mundo, incluindo a própria Europa. $\mathrm{O}$ 
colonialismo, originalmente, se alimentava do desejo por riqueza, recursos naturais e expansão religiosa, sendo o processo de colonização, “frequentemente violento, subjugando indígenas e a população nativa, antes de estabelecer uma estrutura administrativa, militar e econômica para manter a dominação" (NAYAR, 2015, p.30). O colonialismo, invariavelmente conduziu a um binário racial: de um lado a avançada, progressista e modernada Europa, identificada por "Nós" e de outro lado, os atrasados, primitivos e ultrapassados nativos, conhecidos por "Eles" (NAYAR, 2015). Curiosamente, essa questão racial permite afirmar que "as diferenças de colonial e imperial foram construídas em cima da classificação racial”. (MIGNOLO; WALSH, 2018, p. 185, tradução nossa). Do século 16 ao 20, as diferenças coloniais foram ampliadas, modificadas e reproduzidas; estando localizadas na junção de conhecimento, da subjetividade e da classificação racial (MIGNOLO; WALSH, 2018).

É importante observar que o discurso colonial não é simplesmente uma nova expressão para o colonialismo. Ao contrário, sugere uma nova forma de pensamento sobre como os processos econômico, cultural, político e educacional trabalham em conjunto para perpetuar o colonialismo ou para resistir a ele" (PHILLIPS, 2014, p. 153, tradução nossa).

Essa perpetuação do colonialismo se traduz em violência colonial, que "pode ser entendida dentro de uma dimensão 'epistêmica', evidenciando-se como um ataque às ideias, aos valores e às instituições culturais dos povos colonizados" (LOOMBA, 1998, p. 54). Tornase então, necessário avaliar como "esterótipos, imagens e as diferentes generalizações culturais estão lincadas a instituições que exercem algum controle econômico, judicial ou administrativo, incluindo o controle exercido pelas escolas e universidades" (PHILLIPS, 2014, p. 153, tradução nossa). Entretanto, é importante observar o que enfatiza Hobsbawn (1997, p. 103):

\footnotetext{
não se deve negligenciar as distorções das sociedades coloniais - por exemplo, pela mutilação de sua hierarquia, econômica e social - que também decorrem da colonização, mas o interesse na situação colonial não depende da suposição de que a sociedade colonial seja uma réplica da não-colonial.
}

Tal observação enfatiza a relevância da distinção entre colonialismo e colonialidade. Enquanto que colonialismo remete sobretudo ao período das conquistas, dos assentamentos e do controle administrativo sistemático europeu em suas colônias (NAYAR, 2015), a colonialidade refere-se a "uma estrutura complexa que tem vindo a provar, nos últimos 500 anos, ser mais profunda e duradoura que o colonialismo" (QUIJANO, 2010, p. 84); diz respeito aos seus efeitos continuados. Entretanto, foi gerada dentro deste, sem o qual não teria sido imposta na intersubjetividade do mundo, de modo tão engastado e por tanto tempo Walsh (2018, p. 16, tradução nossa) ressalta que 
o controle do trabalho e da subjetividade; as práticas e as políticas de genocídio e de escravidão; o roubo da vida e da terra e as negações e a destruição do conhecimento, da humanidade, da espiritualidade e da cosmo-existência tornaram-se o modus operandi desse novo modelo e padrão de poder que mais tarde viajou pelo mundo.

Segundo essa concepção, o fim do colonialismo não desfez a colonialidade. Por trás da retórica "que promete felicidade e salvação por vias da conversação, do progresso, da civilização, da modernização, do desenvolvimento e da democracia de mercado" (MIGNOLO, 2018, p. 142, tradução nossa), a narrativa da modernidade constrói campos de representação que naturalizam a expansão perpetuada do capitalismo e a reinscrição da humanidade em uma hierarquia radical.

Ao fim do colonialismo, o chamado pós-colonialismo tem um sentido cronológico. Desde os anos 1970, as teorias pós-coloniais estão envolvidas no debate a respeito do modo que as experiências coloniais são representadas e os efeitos que a colonização produziu sobre colonizados e colonizadores. Quando aplicadas à educação, as teorias pós-coloniais enfatizam a importância de entender o vínculo entre globalização e educação, especialmente quanto à necessidade de entender as políticas e práticas educacionais à luz do legado histórico e das forças culturais emergentes locais. Nesse sentido, desnuda-se ao pós-colonialismo não apenas seu caráter teórico, mas também político, de modo que as análises pós-coloniais procuram entender por que as desigualdades globais se perpetuam (PHILLIPS, 2014).

Em contraponto, Young (2003, p. 7) argumenta que o "pós-colonialismo procura mudar a forma das pessoas pensar e o modo de se comportar, para produzir uma relação mais justa e imparcial entre as nações". Entretanto, críticas mais amplas à teoria pós-colonial (PHILLIPS, 2014) estão relacionadas à forma com que o discurso destaca as condições econômicas e sociais como sendo as principais fontes da opressão e da marginalização:

\footnotetext{
Inobstante, a teoria pós-colonial ter alertado para o fato de, longe de ser secundária à questão econômica, a cultura tem que ser vista como essencial à produção e manutenção das relações coloniais. Neste sentido, as teorias póscoloniais têm o potencial de nos ajudar a entender como persistem as desigualdades globais e as ameaças à continuidade e respeito às culturas e tradições locais, em favor de uma cultura de consumo, ancorada nas tradições colonialistas. (PHILLIPS, 2014, p. 154, tradução nossa).
}

Ao confrontar as críticas à análise que a Teoria Pós-Colonial faz a respeito das práticas culturais contemporâneas, há que se ressalvar sua possibilidade de ajudar a entender os inúmeros modos de formação educacional possíveis derivados da articulação entre globalização e educação. Para Mignolo (2011) é possível se fazer três tipos de críticas à modernidade: (1) uma crítica eurocentrada da modernidade, que deriva da própria história interna da Europa; (2) 
a ideia de civilização ocidental e de desocidentalização, esta oriunda da Ásia e presente em outras partes do mundo; e (3) o foco na colonialidade, na pós-colonialidade ou na decolonialidade:

[...] parece mais fácil para os intelectuais europeus aceitar o pensamento póscolonial do que o decolonial. Nada impede que um corpo branco na Europa Ocidental possa sentir como a colonialiade opera nos corpos não-europeus. Compreendê-lo consiste em uma tarefa racional e intelectual, não experiencial (MIGNOLO, 2017, p. 27).

Restrepo e Rojas (2010), nessa linha, identificam os principais aspectos que diferenciam a inflexão decolonial da teoria pós-colonial. A decolonialidade remonta à colonização da América Latina e do Caribe, entre os séculos 16 e 19, no contexto da "primeira modernidade", enquanto que os estudos pós-coloniais se referem à colonização da Ásia e da África, dos séculos 18 a 20 . Os autores ainda ponderam que

\begin{abstract}
essas distinções não significam que não se possa trazer certas confluências entre a inflexão decolonial e as teorias ou estudos pós-coloniais. Uma das mais óbvias é a preocupação de como certas relações de poder associadas às experiências históricas de sujeição colonial têm implicações em nosso presente. (RESTREPO; ROJAS, 2010, p. 24, tradução nossa).
\end{abstract}

Em outras palavras, a pós-colonialidade e a decolonialidade andam em uma mesma direção, porém seguindo caminhos diferentes (MIGNOLO, 2011). De acordo com Nayar (2015, p. 30, tradução nossa), "os estudos pós-coloniais, ganham sentido ao tentar escapar da forma colonial de pensar cultural, intelectual e filosoficamente". Uma vez que a hegemonia intelectual europeia forjou instrumentos como leis, educação, religião e literatura para que a colônia visse o mundo segundo os olhos da Europa, "a decolonização se torna necessária se existe o desejo de fugir das armadilhas do pensamento europeu, permeando a cultura e a visão formal dos assuntos relacionados a colônia" (NAYAR, 2015, p. 45, tradução nossa). Contudo, finalmente observa Nayar (2015, p. 46, traduação nossa):

A descolonização como projeto de independência intelectual, cultural, econômica e política da nação-estado pós-colonial, está seriamente solapada pela globalização vigente a partir do século 20, pois esta impõe padrões, normas e produtos culturais, além de tratados políticos e econômicos do 'Primeiro Mundo', que provocam uma erosão nas nações do 'Terceiro Mundo".

Dado que, seja "na economia e na academia, os modelos do Norte determinam o debate, as políticas e as ações governamentais e institucionais, os mesmos controlam o fluxo das ideias" (NAYAR, 2015, p. 115, tradução nossa), Phillips (2014) admite existir um débito com o Terceiro Mundo. Nesse sentido, reconhece "um perigo na omissão das injustiças globais, 
praticadas para com o colonialismo e o neocolonialismo" (PHILLIPS, 2014, p. 330, tradução nossa). Alguns críticos reconhecem, em relação a esse novo colonialismo, que todas as trocas entre as nações industriais avançadas e o Terceiro Mundo são intrinsecamente injustas e se constituem na melhor receita para a manutenção da pobreza (LANDES, 1998). Ramos (1995, p. 36), tratando do contexto brasileiro, argumenta que

\begin{abstract}
a cultura brasileira não poderia furtar-se à lógica da situação colonial. País descoberto e formado por colonização, teria de percorrer forçosamente todas as fases do processo colonial. Assim, a raridade daquele compromisso é sociologicamente ordinária e compreensível, tendo em vista a lógica da situação colonial em que à exploração econômica se aliam outras formas complementares de dependência, como a assimilação, a aculturação, a associação. É preciso notar que é apenas de grau e não de natureza a diferença entre a situação colonial e certas formas de paz, como a pax lusa, a pax britânica, a pax ianque, em relação ao nosso país. A situação colonial, posta em questão hoje por sociólogos e economistas, é entendida como um complexo, uma totalidade que impõe certo tipo de evolução e de psicologia coletiva às populações colonizadas.
\end{abstract}

Para Ramos (1995), essa psicologia coletiva é assimilada e tacitamente concorda com uma dependência, com o bilinguismo, com uma duplicidade psicológica, e aceita as condições que tornam limitadíssimas as possibilidades de identificação da personalidade do colonizado com a sua circunstância histórico-natural imediata, reforçando assim a anuência de seu caráter neocolonial.

\title{
3 OS IMPACTOS DA NOVA HEGEMONIA E DA CONTRA-HEGEMONIA NA INTERNACIONALIZAÇÃO DA EDUCAÇÃO SUPERIOR
}

A noção de hegemonia remete à filosofia, tendo sido utilizada na tradição pitagórica para "designar um princípio supremo, o qual pode ser o número ou a noção de harmonia" (MORA, 1978, p. 122). Entretanto, foram os estóicos que etabeleceram a distinção entre o "princípio diretivo (hegemônico) de caráter racional” (MORA, 1978, p.107) e a linguagem:

\footnotetext{
Mas quem empregou a noção num sentido filosófico estrito foram os estóicos. Para os representantes do estoicismo antigo e médio (Crisipo, Posidónio) o hegemônico pode referir-se ao cosmos e ser um princípio material, como a terra e, sobretudo, o fogo. Mas com frequência se refere à alma e em especial à 'parte diretora da alma', quer dizer, à parte racional. Esta 'parte diretora' é tão importante para os estóicos que, na realidade, não é propriamente uma parte, mas a própria alma, enquanto princípio unificante de todas as operações mentais. Isto não significa que o hegemônico seja algo espiritual; fiéis ao seu corporalismo, os estóicos supunham que havia uma espécie de 'matéria racional', da qual era composto o hegemônico (MORA, 1978, p. 122).
}

Portanto, para os estóicos, "hegemonia é a razão que anima e governa o mundo" 
(ABBAGNANO, 2007, p. 497). Abbagnano (2007) se reporta a Cícero, que admitia ser a hegemonia a parte mais digna do poder e do domínio sobre tudo e todos. Em outra perspectiva, reforça-se que "para os gregos, hegemonia significava liderar" (HONDERICH, 1995, p. 920, tradução nossa).

O exposto parece se reforçar no sentido etimológico da palavra, em que hegemonia significa "influência dominadora de uma nação sobre outra, o que etimologicamente aponta para liderança" (AYTO, 2005, p. 267). Entretanto, se a palavra 'hegemonia' for associada a Gramsci, "representa a dominação dissimulada de todas as posições do poder institucional e a influência de seus membros, representando apenas uma classe social" (BLACKBURN, 1996, p.169, tradução nossa). Para Gramsci, a hegemonia de uma classe social poderia adiar, indefinidamente a revolução, sendo que para esta ocorrer, seria necessário infiltrar-se no sistema e conseguir quebrar as estruturas de poder dominantes (BLACKBURN, 1996).

Assim, o conceito de hegemonia, cunhado como o "consentimento espontâneo dado pelas grandes massas da população à direção geral imposta à vida social pelo grupo fundamental dominante" (GRAMSCI, 1971, p. 12), é indispensável ao entendimento das diferentes formas de manifestação dos fenômenos sociais nas sociedades capitalistas, nas quais as práticas hegemônicas são confundidas com as práticas desejáveis e o pensamento hegemônico se apresenta como pensamento único (OREGIONI, 2015).

Gramsci modificou o materialismo histórico ortodoxo dando um papel independente à consciência humana. Usou esse 'insight' para desenvolver o conceito de hegemonia, ou poder ideológico, para explicar a resiliência da democracia liberal e o avanço das nações industrializadas. Argumentou que a ordem para derrubar o estado nesses países, consistia em partidos revolucionários focados, primeiramente, em superar as fontes do poder hegemônico com a sociedade civil, tais como igrejas, escolas e a mídia. (HOMDERICH, 1995, p. 871, tradução nossa).

Os teóricos da hegemonia neo-gramsciana e herdeiros da Teoria Crítica entendem a educação capitalista como instrumento corporativo de poder e dominação, incidindo sobre este modelo educacional as maiores críticas (KELLNER, 2003). Hegemonia, portanto, não é simplesmente uma conquista militar e a dominação pela força. Na visão dos teóricos marxistas, se trata de um trabalho mais insidioso, dissimulado. Uma vez que a hegemonia é eficientemente assimilada, tem-se a formação do sujeito colonial: "Hegemonia é, então, dominação pelo consentimento e não pela coerção, como argumenta Gramsci. [...]. O sujeito aceita sua inferioridade e ignorância e, implicitamente, concede à Europa o direito de lhe regular" (NAYAR, 2015, p. 87, tradução nossa). 
Dada a centralidade do conhecimento na matriz de poder colonial e a autoridade atribuída à universidade ocidental como local privilegiado de produção desse conhecimento (Bhambra et al., 2018) - já que desfruta de uma autoridade epistemológica que lhe confere o poder para decidir quais histórias e contribuições intelectuais são válidas e merecedoras de atenção e de disseminação (Gebrial, 2018) - a discussão em torno da hegemonia na educação superior envolve aspectos como a estrutura universitária e os tipos de conhecimento produzidos, além das relações estabelecidas nesse domínio.

O clássico paradigma marxista vê a educação funcionando como um sistema hegemônico social que é organizado por, e serve ao interesse do capital, enquanto a mesma clama por modelos educacionais alternativos que preparem estudantes e cidadãos para um modelo socialista progressivo de organização social (KELLNER, 2003, p. 163).

Trata-se, portanto, de um espaço não neutro, cujas práticas e critérios universalistas eliminam, selecionam, reproduzem e legitimam desigualdades sociais (Bordieu \& Passeron, 2009).

A universidade esteve intimamente associada à formação dos estados-nação e das elites capitalistas ao longo da história. Durante período colonial, foi local chave para a institucionalização e a naturalização das relações de apropriação e exploração, além de ter se beneficiado diretamente de tais relações. Bhambra, Gebrial e Nisancioglu (2018, p. 5, tradução nossa) sintetizam esse entendimento:

Foi na universidade que intelectuais coloniais desenvolveram teorias de racismo, popularizaram discursos que reforçaram o apoio aos esforços coloniais e forneceram os fundamentos intelectuais e éticos para a desapropriação, a opressão e a dominação dos sujeitos colonizados. Nas metrópoles coloniais, as universidades forneciam aos administradores das colônias conhecimentos sobre os povos que governariam, bem como lições sobre técnicas de dominação e de exploração.

O modelo acadêmico dominante segue em grande medida imerso em um padrão de poder moderno/colonial. Os critérios que definem aspectos como o currículo e os corpos docente e estudantil baseiam-se na ideologia que reforça a superioridade de uma cultura específica, de modo que divisões disciplinares, modelos teóricos e histórias eurocentradas continuam a prover materiais intelectuais que reproduzem e justificam hierarquias (SOUSA SANTOS, 2018). Soma-se ao exposto o fato de que os produtores das teorias legitimadas como 'universais' são quase sempre homens europeus ou euro-americanos, às custas da desqualificação e da "inferiorização dos conhecimentos produzidos por homens e mulheres de todo o planeta" (GROSFOGUEL, 2016, p. 25).

Ao subjugar epistemologias locais em favor do eurocentrismo, o conteúdo do 
conhecimento universitário permanece governado 'pelo Ocidente' e 'para o Ocidente', enquanto que formas de conhecimento não ocidentalizadas são celebradas como 'culturas locais'; comodificadas e apropriadas em benefício do Ocidente; ou simplesmente não reconhecidas (STEIN; ANDREOTTI, 2016; MBEMBE, 2016; BHAMBRA; GEBRIAL; NIŞANCIOĞLU, 2018; GEBRIAL, 2018; SOUSA SANTOS, 2018).

A universidade é, portanto, uma instituição gerida por atores suscetíveis às crenças ocidentais e aos efeitos da totalidade do conhecimento (MIGNOLO, 2018). Além das divisões disciplinares, dos currículos e das ementas; dos conteúdos de pesquisa e ensino e dos métodos de ensino e aprendizagem, a colonialidade universitária alcança aspectos como o acesso docente e estudantil; a estrutura e a governança; bem como as relações entre a universidade e a sociedade (MBEMBE, 2016; BHAMBRA; GEBRIAL; NIŞANCIOĞLU, 2018; SOUSA SANTOS, 2018).

Nas colônias, a fundação da universidade e a imposição do modelo universitário europeu resultaram da articulação entre capitalismo global e a disponibilidade de recursos imperiais, com o propósito de expandir a lógica totalizadora da dominação. Tais intervenções ocorreram inicialmente na América hispânica, a partir da metade do Século 16, e posteriormente na Ásia, na África e no Pacífico, e assumiram diferentes formas, alcançando mesmo os territórios não sujeitados por um longo período de tempo à colonização europeia (SOUSA SANTOS, 2018).

No Sul Global, a universidade foi desde seu início moldada por um Norte Global hegemônico, com seu projeto civilizatório de modernidade e por meio do privilégio adquirido pela ciência moderna como mecanismo de progresso e principal forma de razão (Sousa Santos, 1988). Tais intervenções trouxeram consigo tanto o modo de produzir e organizar o conhecimento - "colonial/moderno, capitalista e eurocentrado" (QUIJANO, 2005, p. 122) quanto culminaram em dependências, objetivas e subjetivas, por meio de alinhamentos com Governos e universidades do Norte. O conhecimento ocidental tornou-se, portanto, uma commodity de exportação da modernização (Mignolo, 2011). Não por acaso, a universidade ocidental tende a ser vista como o modelo ideal de universidade nesses contextos (ROBERTSON; KOMLJENOVIC, 2016; STEIN; ANDREOTTI, 2016; BHAMBRA; GEBRIAL; NIŞANCIOĞLU, 2018).

O contexto de pós Segunda Guerra mundial inaugurou uma nova era de abordagens para o tratamento da educação superior nesses territórios, sendo que muitos dos esforços se deram sob o título de 'desenvolvimento internacional'. Entre as articulações conduzidas, podemos mencionar a constituição de uma 'missão internacional' para a universidade; o estabelecimento 
de programas nacionais e regionais de 'ajuda técnica'; bem como a formação de estudantes/professores universitários das ex-colônias nos países centrais, que lhes confeririria os conhecimentos especializados requeridos para liderar seus países nos 'rumos da modernização' (OREGIONI, 2015; ROBERTSON; KOMLJENOVIC, 2016; STEIN, 2017).

Os anos 1990 forneceram terreno para um novo ciclo de intervenções do Norte nos rumos dos sistemas educacionais e das universidades do Sul. Na América Latina, a submissão dos países às políticas neoliberais e de ajustamento estrutural, sua consequente dependência aos fundos do Banco Mundial e as condições impostas à expansão de setores nacionais como a educação fizeram com que a relação entre as instituições universitárias, dependentes de financiamento público, e os Estados se tornasse particularmente problemática à sua sobrevivência (Robertson; Komljenovic, 2016).

A tentativa de contorno dessa crise se deu por meio de ações como a inserção do setor privado; o estabelecimento de novas fontes de financiamento por meio de empréstimos e outros arranjos fiscais; o comércio transfronteiriço de serviços educacionais; o financiamento de estudos no exterior e a criação de capacidades por meio de parcerias com universidades do Norte (LEITE; GENRO, 2012; ROBERTSON; KOMLJENOVIC, 2016). A partir dos anos 2000, a histórica articulação entre capitalismo e colonialismo universitário/acadêmico adquire novos contornos e se traduz em pressões, frequentemente subjetivas, para que a instituição universitária se ajuste e se submeta aos critérios de relevância e eficácia do capitalismo global (SOUSA SANTOS, 2018).

Uma vez que a globalização em curso seja compreendida como uma trajetória de longo prazo do sistema mundial capitalista (WALLERSTEIN, 2006); um processo cuja racionalidade específica, o eurocentrismo, somente pode ser compreendida por meio da familiarização com o padrão de poder estabelecido no período colonial (QUIJANO, 2005; MIGNOLO, 2011), o capitalismo universitário/acadêmico se apresenta como um desenvolvimento recente, mas reflete uma longa continuidade histórica.

Com base nessa percepção, a formação de um discurso consensual e hegemônico, de ordem política e acadêmica, em torno da ideia de internacionalização da educação superior pode ser altamente funcional ao atual estágio do capitalismo global em curso. Nessa configuração específica, a universidade é capitalista não somente por estar a serviço da reprodução de uma sociedade capitalista (como sempre esteve historicamente); mas pela sua capacidade de produzir para o mercado mundial e projetar-se a si mesma como mercadoria.

A constituição da internacionalização da educação superior como um objeto/fenômeno de estudo contemplou, de início, a saga por uma definição 'genérica' para o termo, que fosse 
aplicável a diferentes países, culturas e sistemas educacionais. Sem dúvidas, o conceito mais amplamente adotado pela literatura é o fornecido por Knight (2004, p. 11, tradução nossa), que define internacionalização como "o processo de integração das dimensões internacional, intercultural e global aos propósitos, às funções primárias e à entrega da educação póssecundária”, com vistas ao alcance ou ao aprimoramento de objetivos de diferentes naturezas. Trata-se, nessa ótica, de um meio para a consolidação de um fim; de um processo com valor instrumental (DE WIT, 1998; KNIGHT, 2004, 2015; HUNTER; DE WIT; HOWARD, 2016).

A compreensão das motivações e dos interesses pelos quais um país ou instituição universitária investe em internacionalização tem relevância à medida que reflete os valores que guiam esse processo. Os estudos de Knight e De Wit (1995), De Wit (1998) e Knight (2004) são marcos nas discussões sobre as rationales subjacentes à internacionalização e fazem referência à diversidade de atores envolvidos nesse cenário, tais como: instituições universitárias, dos governos nacionais, dos organismos internacionais e do setor privado, além dos próprios participantes. No geral, tais atores não se engajam ao processo devido a uma única rationale, mas por uma combinação de motivações e interesses, hierarquizados em termos de prioridade, que podem se alterar com o tempo e a depender do país e da região.

O fato é que, seja em nível global, regional, nacional, institucional ou individual, a internacionalização da educação superior é um dos fatores que mais criticamente tem afetado a educação superior no mundo (KNIGHT; DE WIT, 2018; DE WIT, 2019). Trata-se de um discurso comumente tratado em termos de 'necessidade estrutural', 'imperativo' ou 'obrigação', cuja filosofia associada é a crença generalizada sobre a inevitabilidade do processo (Lima \& Contel, 2011), tendo em vista o contexto de globalização e 'competitividade' (OREGIONI, 2015).

Para Morosini et al. (2006, p. 97), desenha-se, em meio à ênfase dada à internacionalização, uma era neocolonialista na educação superior: "Refere-se a uma nova era de poder e influência, na qual corporações multinacionais, conglomerados de mídia e grandes universidades procuram dominar o mercado do conhecimento não só por razões políticas e ideológicas, mas, principalmente, por ganhos comerciais." Para autores como Altbach (2004) e Morosini et al. (2006), os governos não estão inteiramente fora deste quadro de negociações; eles oferecem apoio e alguma assistência às organizações que estão atuando em seus países, mantendo um interesse residual em deter essa influência. No específico, o resultado se repete na perda da autonomia cultural e intelectual pelos menos poderosos. Tal imposição, contudo, não ocorre de modo teleológico, nem por determinação ou opressão; são movimentos sedutores e 'racionais' de convencimento que naturalizam práticas específicas como necessárias (LEITE; 
GENRO, 2012).

Considerando a perspectiva hegemônica; um posicionamento unilateral, discricionário, inflexível em sua essência e impositivo, dissimulado e insidioso quanto a prática, mais do que o sentido de conduzir ou liderar classicamente atribuído, parece refletir melhor o sinônimo de hegemonia. É, portanto, por meio de um processo de assimilação que o colonizado passa a acreditar em novas representações e a valorizá-las em seu contexto, ratificando sua inferioiridade e ignorância e aceitando de modo consensual a superioridade ética, moral e cultural da classe ou coalizão dominante. Configura-se, então, a prevalência da hegemonia quando se constata a união entre uma configuração material do poder com um conjunto de ideias sobre a ordem mundial e a anuência das instituições envolvidas num dado processo específico.

Ao adotarmos a decolonialidade como base epistemológica, entendemos que a perspectiva de internacionalização se encontra imersa na matriz cultural do poder colonial e atua sob o alicerce de um imaginário global dominante, que se esconde atrás da retórica da modernidade e que permite aos centros hegemônicos comandarem os rumos da educação superior mundial em conformidade com os seus interesses (LEAL; MORAES; OREGIONI, 2018, p. 117).

De fato, se pode reconhecer a crescente predominância, no contexto internacional, de um modelo mercantil de educação superior, que se distancia diametralmente de um paradigma institucional e político-pedagógico da universidade pública, uma vez que este modelo não aceita:

que as relações entre os públicos relevantes sejam relações mercantis; que a eficiência, a qualidade e a responsabilização educacional sejam definidas em termos de mercado; que se generalize, nas relações professor-aluno, a mediação tecnológica (assente na produção e consumo de objetos materiais e imateriais); que a universidade se abra (e se torne vulnerável) às pressões dos clientes; que a concorrência entre 'os operadores do ensino' seja o estímulo para flexibilidade e adaptabilidade às expectativas dos empregadores (leia-se o recrutamento de estudantes) com mais alto retorno para o capital investido (SOUSA SANTOS, 2011, p. 31).

Torna-se consequente uma pressão pelo abandono desse paradigma, sobretudo no que concerne às instituições públicas, em prol de um viés mais empresarial, que mais efetivamente viabilize os imperativos hegemônicos.

Observa-se, assim, que ao lado das oportunidades que a internacionalização da educação superior oferece, há questões políticas e éticas que são contraditórias e contestáveis (STEIN, 2017; MWANGI et al., 2018). Todavia, muito frequentemente tais dilemas são tratados de forma factual ou naturalizada, sem o aprofundamento da sua relação com o contexto mais amplo 
em que a educação superior se insere, sobretudo historicamente. Como Bedenlier, Kondakci e Zawacki-Richter (2018, p. 128, tradução nossa) argumentam em sua revisão de literatura sobre os principais temas abordados pelo Journal of Studies in International Education no período de 1997 a 2016, “a pesquisa e a prática precisam questionar de forma autocrítica os entendimentos e as abordagens da internacionalização no que diz respeito à sua contribuição para a desigualdade e dependência entre os sistemas de ensino superior e a consolidação da dominância ocidental”.

Quando tal contextualização ocorre, a tendência é que se faça referência ao vínculo entre internacionalização e globalização, com ênfase em uma tensa relação entre os dois fenômenos, com conotação positiva para o primeiro e negativa para o segundo. Por exemplo, argumenta-se que enquanto a internacionalização busca incorporar à educação superior diferentes perspectivas e modelos por meio do intercâmbio entre nações e culturas, com vistas a descobrir maneiras de explorar as diferenças para o 'bem maior'; a globalização promove um modelo de homogeneização cultural, social, política e tecnológica para viabilizar maior integração e interdependência (MARINGE et al., 2013).

De uma perspectiva crítica, contudo, a internacionalização pode ser considerada um agente da globalização e um fenômeno de interesse do capital. Nesse sentido, não está perdendo o seu rumo, como a grande maioria dos discursos acadêmicos sobre o tema afirma. Afinal, para os situados 'deste lado da linha abissal' - a divisão metafórica, invisível, antes epistêmica e política do que geográfica, que separa as sociedades metropolitanas dos territórios coloniais desaparecem enquanto realidade (SOUSA SANTOS, 2010) - as relações internacionais na educação superior, objetivas ou subjetivas, nunca foram igualitárias.

Tendo por referência os conceitos de hegemonia, atividades de internacionalização poder ser consideradas não-hegemônicas quanto se desvinculam dos parâmetros tradicionais da lógica do capitalismo global, orientados pelos interesses dos centros mundiais de produção do conhecimento. Tornam-se contra-hegemônicas quando encontram instrumentos que lhes permitem desenvolver ações opostas a essa lógica (OREGIONI, 2017; LEAL; MORAES; OREGIONI, 2018). Evidencia-se, então, o papel desempenhado pelo Estado na construção de alternativas contra-hegemônicas:

O segundo protagonista da resposta aos desafios é o Estado nacional sempre e quando ele optar politicamente pela globalização solidária na universidade. Sem esta opção, o Estado nacional acaba por adotar, mais ou menos incondicionalmente, ou por cedes, mais ou menos relutantemente, às pressões da globalização neoliberal e, em qualquer caso, transformar-se à no inimigo da universidade pública por mais proclamações que faça em contrário 
(SOUSA SANTOS, 2011, p. 60).

Essa perspectiva de internacionalização não hegemônica ou contra-hegemônica, independentemente de compreender a educação como direito e bem publico, não a contesta; reconhece a necessidade da inclusão social e da integração regional, ao tempo em que admite e aceita a preservação das particularidades de cada cultura, enfatizando a reciprocidade, a horizontalidade, a complementaridade e a solidariedade com princípios para a cooperação internacional acadêmica. Reiterando Mignolo (2017): “em termos decoloniais, a concepção de internacionalização contra-hegemônica habita a fronteira e pensa na fronteira; é epistemologicamente desobediente; confronta histórias locais com projetos globais" (LEAL; MORAES; OREGIONI, 2018, p. 118).

Um importante antecedente histórico referente ao conceito latino-americano de “internacionalização contra-hegemônica” é o Movimento de Córdoba, de 1918, no qual foram levantadas bandeiras em defesa da autonomia universitária (LEAL; MORAES; OREGIONI, 2018; PROLO, 2019; LEAL, 2020). Um grupo de estudantes da Universidad de Córdoba, valendo-se do chamado Manifiesto Liminar, iniciou um Movimento de Reforma Universitária que, no transcurso de uma década, teve repercussões continentais, ecoando em vários países da região. Essa iniciativa desenha uma nova história, para a ideia de Universidade pública latinoamericana (MOROSINI et al., 2006). O discurso dos universitários é impregnado por um forte caráter idealista, associado a um componente geracional:

\footnotetext{
O Movimento da Reforma pode ser encarado como um libelo contra o imperialismo de toda a ordem, as oligarquias locais e a influência conservadora da Igreja na universidade. É um processo de busca da identidade cultural latino-americana: um movimento social integrador, contra fronteiras nacionais, que, em termos ideais, procura atualizar o projeto frustrado de unificação da América Latina (MOROSINI, et al., 2006, p. 184).
}

Segundo Morosini et al. (2006), a ideia de universidade sugerida pela Reforma era de uma instituição humanista, interessada no que se passasse no mundo; iluminista, orientando a construção de uma nova sociedade e científica, combatendo o verbalismo de cátedras anacrônicas. Para Alexandre (2015, p. 29), com o Movimento de Córdoba levantaram-se "bandeiras em defesa da autonomia universitária, da mudança no processo de ensino e de docência, da democratização da universidade, tanto em sua gestão quanto na garantia da permanência e participação de estudantes de todos os grupos sociais", marcando, Segundo Prolo (2019), o surgimento de uma corrente universitária tipicamente latino-americana, cujo principal legado consiste no engajamento da Universidade com a justiça social na busca de uma sociedade mais igualitária e democrática. 
Seus princípios essenciais contemplam a autonomia universitária nos aspectos político, acadêmico, administrativo e econômico; a eleição dos corpos diretivos e das autoridades da instituição pela própria comunidade universitária; a gratuidade do ensino; a democratização do acesso e a assistência social aos estudantes; a extensão e o fortalecimento da função social da universidade; a unidade latino-americana (RUBIÃO, 2013; DALMASSO, 2018). Juntos, tais princípios relacionam-se à ideia de que a Universidade se destina a cumprir um papel fundamental na transformação da sociedade (DALMASSO, 2018).

No entanto, é importante realçar que a América Latina é uma região na qual as tendências contemporaneamente evidenciadas na Educação Superior têm sido altamente funcionais ao atual estágio do capitalismo global em desenvolvimento (GOMES; ROBERTSON; DALE, 2012). Para contrapor tais tendências, Leal, Moraes e Oregioni (2018), inspiram-se na ideia de uma outra globalização, de Milton Santos, para o qual as mudanças necessárias à 'globalização como perversidade' advirão dos países do Sul:

\begin{abstract}
É previsível que o sistemismo sobre o qual trabalha a globalização atual ergase como um obstáculo e torne difícil a manifestação da vontade de desengajamento. Mas não impedirá que cada país elabore, a partir de características próprias, modelos alternativos, nem tampouco proibirá que associações do tipo horizontal se deem entre países vizinhos igualmente hegemonizados, atribuindo uma nova feição aos blocos regionais e ultrapassando a etapa das relações meramente comerciais para alcançar um estágio mais elevado de cooperação. Então, uma globalização construída de baixo para cima, em que a busca de classificação entre potências deixe de ser uma meta, poderá permitir que preocupações de ordem social, cultural e moral possam prevalecer (SANTOS, 2013, p. 154)
\end{abstract}

Dada essa complexidade e, aos céticos, a ratificação de uma perspectiva utópica da educação superior, considera-se que o quadro evidenciado suscita o desenvolvimento de estudos empíricos que, em referência a Santos (2013), investiguem sob quais circunstâncias uma 'outra internacionalização da educação superior' seja viável ou possível (LEAL; MORAES; OREGIONI, 2018).

Os desafios de um novo modelo de internacionalização da educação superior, amparado em princípios de contra-hegemonia e decolonialidade, requer a solução de problemas complexos e um pensamento efetivamente inovador, no qual a multi, a inter e a transdisciplinariedade sejam práticas institucionais reais, compreendendo um novo olhar que é antes substantivo do que instrumental. Pensar as relações internacionais e interculturais a partir de uma ótica que, no lugar de suprimir, compreenda a multiplicidade de funções que podem ser atribuídas à instituição universitária - incluindo seu papel no debate sobre futuros alternativos e na decolonialidade do poder, do saber e do ser - significa romper com a hegemonia de visões e enquadramentos vinculados a uma ordem global específica (LEAL, 2020). Em outros termos, 
implica em distanciar-se dos pressupostos eurocentrados enquadrados como universais e de suas promessas de progresso, felicidade e salvação, parar vislumbrar um "horizonte aberto a múltiplas possibilidades" (RAMOS, 1967, p. 24) ou uma "agenda de total desordem" (FANON, 2004, p. 2).

A decolonialidade não emerge de uma genealogia conceitual universalista. Se assim o fosse, cairia em uma visão moderna do conhecimento e da epistemologia vinculados a projetos globais. Trata-se de uma epistemologia que clama pela legitimidade de diferentes perspectivas epistemológicas para além da dominante; pelo direito de ser 'epistemicamente desobediente', no sentido de construir um mundo no qual diferentes mundos coexistam (LEAL, 2020). Como Mignolo (2017, p. 17) observa, "se nos dirigirmos à modernidade, permaneceremos presos à ilusão de que não há outra maneira de pensar, fazer e viver”.

Considera-se que os limites de propor modelos específicos de inserção internacional residem sobretudo no risco de reproduzir dicotomias coloniais, portanto, não há um único caminho para (re)imaginar a internacionalização da educação superior. Cabe lembrar, aqui, que a opção decolonial "requer desobediência epistêmica, porque o pensamento fronteiriço é por definição pensar na exterioridade, nos espaços e tempos que a auto-narrativa da modernidade inventou como seu exterior para legitimar sua própria lógica de colonialidade" (MIGNOLO, 2017, p. 30).

\section{CONSIDERAÇÕES FINAIS}

Diante da relevância do rastreamento de iniciativas de internacionalização da educação superior desvinculadas da colonialidade imbricada ao contexto universitário, o objetivo deste ensaio de propor uma análise crítica e reflexiva do fenômeno da internacionalização da educação superior, a partir dos conceitos estruturantes associados a globalização, (contra)hegemonia e (de)colonialidade. Lamentavelmente, o caráter analítico-crítico do presente ensaio não trouxe, em si, todas as respostas desejadas.

Um dos limites da reflexão se deve ao fato de que os referenciais teóricos tendem a conceber os conceitos inerentes a globalização, (contra)hegemonia e (de)colonialidade de forma dicotômica, sem considerar a realidade híbrida, conflitante e complexa da educação superior. A coexistência de conceitos e interpretações apontam para a possibilidade de um novo pensar e para eventuais novas considerações, não necessariamente aqui consignadas. Por outro lado, ao considerar-se as múltiplas interpretações e concepções conceituais inerentes às ideias tratadas, o texto pode ser funcional ao entendimento das dinâmicas contemporaneamente 
evidenciadas e à formulação de políticas e estratégias de internacionalização no âmbito da gestão universitária publica, sobretudo ao se tratar de fenômeno pouco explorado em termos epistemológicos e frequentemente tratado com fortes pressões políticas pelos discursos dominantes.

É possível, ou mesmo provável, que ao se cotejar a análise conceitual com a praxis da internacionalização da educação superior seja suscitada a pior das considerações: Que no contexto dessa internacionalização, as instituições de educação superior, ao mimetizarem modelos exógenos, sejam adeptas de um isomorfismo organizacional, que as mantém distantes de uma prática substantiva de internacionalização. Entretanto, ao considerar a perspectiva hegemônica como um posicionamento unilateral, discricionário, inflexível em sua essência e impositivo, dissimulado e insidioso, reserva-se a expectativa de encontrar na contra-hegemonia e na decolonialidade o conforto e o reforço da autonomia institucional universitária e da real identidade perdida em um processo de internacionalização da educação superior que deixe de ser meramente mimético, instrumental e utilitarista. Pois, provavelmente resida nesses motivos a resistência das instituições de educação superior em ouvir as possibilidades de mudança em seus processos de internacionalização e em sua própria herança colonial, latente no grito silencioso da academia.

\section{REFERÊNCIAS}

ABBAGNANO, N. Dicionário de filosofia. 5 ed. São Paulo: Martins Fontes.

ALTBACH, P. Globalization and the university: myths and realities in unequal world. Tertiary Education and Management, Kluwer Academic Publishers, 2004.

ARAYA J. M. J.; OREGIONI, M. S. Internacionalización de la Universidad en el marco de la integración regional. Buenos Aires, Argentina: Riesal, 2015.

AYTO, J. Dicionário de filosofia. 2 ed. London: A\&C Black, 2005.

BHAMBRA, G.; GEBRIAL, D.; NIŞANCIOĞLU, K. Decolonising the university. 1. ed. London: Pluto Press, 2018.

BERGAMO, P. Educação universitária: práxis coletiva em busca de veraz qualidade e precisa cientificidade. Campina Grande: EDUEPB, 2012.

BLACKBURN, S. The Oxford dictionary of philosophy. Oxford: Oxford Press University, 1996.

BEDENLIER, S.; KONDAKCI, Y.; ZAWACKI-RICHTER, O. Two decades of research into 
the internationalization of higher education: Major themes in the Journal of Studies in International Education (1997-2016). Journal of Studies in International Education, v. 22, n. 2, 108-135, 2018.

BORDIEU, P.; PASSERON, J.-C. A reprodução: Elementos para uma Teoria do Sistema de Ensino. 2. ed. Petrópolis: Ed. Vozes, 2009.

CURREN, R. A companion to the philosophy of education. Oxford: Blackwell Publishing, 2003.

DALMASSO, E. 1918: raíces y valores del movimiento reformista. 1 ed. Córdoba: Editorial de la UNC, 2018.

DE WIT, H. Rationales for Internationalisation of Higher Education. Millennium: Journal of International Studies, v. 11, n. July, p. 1-8, 1998.

FAIRCLOUGH, N. Análise Crítica do Discurso como método em pesquisa social científica. Linha D'Água, v. 25, n. 2, p. 307-329, 2012.

FANON, F. Os condenados da terra. Juiz de Fora: Editora da UFJF, 2004.

GEBRIAL, D. Rhodes must fall: Oxford and Movements for change. In: BHAMBRA, G.; GEBRIAL, D.; NIŞANCIOĞLU, K. (Eds.). . Decolonising the University. 1. ed. London: Pluto Press, 2018. p. 19-36.

GOMES, A., ROBERTSON, S.; \& DALE, R. The social condition of higher education: Globalisation and (beyond) regionalisation in Latin America. Globalisation, Societies and Education, v. 10, n. 2, p. 221-245, 2012.

GRAMSCI, A. Selections from the Prison Notebooks of Antonio Gramsci. New York, EEUU: International Publishers, 1971.

GROSFOGUEL, R. A estrutura do conhecimento nas universidades ocidentalizadas: racismo/sexismo epistêmico e os quatro genocídios/epistemicídios do longo século XVI. Revista Sociedade e Estado, v. 31, n. 1, 2016.

HOBSBAWN, E. J. O choque de civilizações e a recomposição da ordem mundial. Rio de Janeiro: Editora Objetiva Ltda, 1995.

Sobre história. São Paulo: Companhia das Letras, 1997.

HONDERICH, T. The Oxford companion to philosophy. New York: Oxford University Press Inc., 1995.

HUNT, E.K. Era dos extremos: o breve século XX. São Paulo: Companhia das Letras, 1995.

HUNTER, F.; DE WIT, H.; HOWARD, L. Key trends in internationalisation of higher education: are we heading in the right direction? In: STIASNY, M.; GORE, T. (Eds.). . Going global: identifying trends and drivers of international education. 1. ed. London: Emerald Group Publishing Ltd., 2016. 
KELLNER, D. Critical theory. In: CURREN, R. A companion to the philosophy of education. Oxford: Blackwell Publishing, 2003.

KNIGHT, J. Internationalization remodeled: definition, approaches, and rationales. Journal of Studies in International Education, v. 8, n. 5, p. 5-31, 2004.

KNIGHT, J. (2015). International universities: misunderstandings and emerging models? Journal of Studies in International Education, v. 19, n. 2, p. 107-121, 2015.

KNIGHT, J.; DE WIT, H. Strategies for internationalization of higher education: Historical and conceptual perspectives. In: Strategies for internationalization of higher education: A comparative study of Australia, Canada, Europe and the United States of America. European A ed. Amsterdam, The Netherlands, p. 5-33, 1995.

KNIGHT, J.; DE WIT, H. Internationalization of higher education: Where have we come from and where are we going? In: PROCTOR, D.; RUMBLEY, L. (Eds.). . The future agenda for internationalization in higher education: Next generation perspectives into research, policy, and practice. 1. ed. New York and London: Routledge, 2018.

KNOBEL, M.; LIMA, M. C.; LEAL, F.; PROLO, I. Desenvolvimentos da internacionalização da educação superior no Brasil: Da mobilidade acadêmica internacional à institucionalização do processo na universidade. ETD - Educação Temática Digital, v. 22, n. 2, p. 672-693, 2020.

LANDES, D. S. A riqueza e a pobreza das nações: por que algumas são tão ricas e outras tão pobres. Rio de Janeiro: Campus, 1998.

LEAL, F.; MORAES, M. C. B. Decolonialidade como epistemologia para o campo teórico da internacionalização da educação superior. Arquivos Analíticos de Políticas Educativas, v. 26, n. 87, 2018.

LEAL, F., MORAES, M.C.B.; OREGIONI, M. S. Hegemonia e contra-hegemonia no contexto da educação superior: critérios para uma análise crítica e reflexiva do campo. Integración y Conocimento, v. 2, n. 10, p. 106-132, 2018.

LEAL, F. As bases epistemológicas dos discursos dominantes de internacionalização da educação superior no Brasil. Tese (doutorado em Administração). Florianópolis: Universidade do Estado de Santa Catarina, 2020.

LEITE, D.; GENRO, M. E. H. Avaliação e internacionalização da Educação Superior: Quo vadis América Latina? Avaliação: Revista da Avaliação da Educação Superior (Campinas), 17(3), 763-785, 2012.

LIMA, M. C.; CONTEL, F. Internacionalização da educação superior: nações ativas, nações passivas e a geopolítica do conhecimento. São Paulo: Alameda, 2011.

LOOMBA, A. Colonialism/postcolonialism. London, England: Routledge, 1998.

MARINGE, F.; DE WIT, H. Global higher education partnerships: equity and epistemic concerns wit distribution and flows of intellectual capital. In: CÔTÉ, J.; FURLONG, A. (Eds.). 
. Routledge Handbook of the Sociology of Higher Education. 1. ed. New York: Routledge, 2016. p. 299-214.

MARX, K.; ENGELS, F. Manifesto do partido comunista. Livro de Domínio Público, 1951.

MBEMBE, A. J. Decolonizing the university: New directions. Arts \& Humanities in Higher Education, v. 15, n. 1, p. 29-45, 2016.

MIGNOLO, W. The darker side of Western modernity: global futures, decolonial options. Durham \& London: Duke University Press, 2011.

MIGNOLO, W. Eurocentrism and Coloniality. In: WALSH, C.; MIGNOLO, W. (Eds.). On decoloniality: Concepts, analytics, praxis. Duke University Press, p. 194-210, 2018;

MIGNOLO, W. D.; WALSH, C. E. On decoloniality: Concepts, analytics, praxis. Duke University Press, 2018.

MWANGI, C. et al. Criticality in international higher education research: a critical discourse analysis of higher education journals. Higher Education, p. 1-17, 2018.

MORA, J. F. Dicionário de filosofia. Lisboa: Publicações Dom Quixote, 1978.

MOROSINI, M. C. et al. Enciclopédia de pedagogia universitária. Brasília: INEP/MEC, 2006.

NAYAR, P. The postcolonial studies dictionary. Oxford, UK: John Wiley \& Sons, 2015.

OREGIONI, M. S. ¿De qué hablamos cuando hablamos de internacionalización universitaria? In MARTÍNEZ, S. L. (Ed.), Desafíos y dilemas de la universidad y la ciencia en América Latina y el caribe en el siglo XXI, p. 325-332. Buenos Aires, Argentina: Editorial Teseo, 2015.

OREGIONI, M. S. La internacionalización de las universidades latinoamericanas como objeto de estudio. In: ARAYA, J. M. J.; OREGIONI, M. S. (Eds.). . Internacionalización de la Universidad en el marco de la integración regional. 1. ed. Buenos Aires:

PHILLIPS, D.C. Encyclopedia of educational theory and philosophy. Los Angeles: SAGE Publications, Inc., 2014.

POULANTZAS, N. Political power and social classes. London, England: New Left Books, 1973.

PROLO, I. Pertinência do projeto universitário latino-americano para a internacionalização da educação superor: um estudo sobre a UNILA. São Paulo: Escola Superior de Propaganda e Marketing, 2019.

PROLO, I.; VIEIRA, R. C.; LIMA, M. C.; LEAL, F. Internacionalização das universidades brasileiras: Contribuições do Programa Ciência sem Fronteiras. Administração: Ensino e Pesquisa (RAEP), v. 20, n. 2, 2019. 
PURPEL, D. (1999). Moral outrage in education. New York, NY: Peter Lang, 1999.

QUIJANO, A. Colonialidade do poder, eurocentrismo e América Latina. A colonialidade do saber: Eurocentrismo e ciências sociais. Perspectivas latinoamericanas. Buenos Aires: Consejo Latinoamericano de Ciencias Sociales (CLACSO), 2005.

QUIJANO, A. Colonialidade do poder e classificação social. In: SOUSA SANTOS, B. de; MENESES, M. P. (Eds.). Epistemologias do Sul. São Paulo: Cortez, 2010.

RAMOS, A. G. Introdução crítica à sociologia brasileira. Rio de Janeiro: Editora UFRJ, 1995.

RAMOS, A. G. A modernização em nova perspectiva: em busca do modelo da possibilidade. Revista de Administração Pública, Clássicos da Revista de Administração Pública, v. 2, p. 7 42, 1967.

RESTREPO; E. ROJAS, A. Inflexion decolonial: fuentes, conceptos y cuestionamientos. Popayán, Colombia: Editorial Universidad del Cauca, 2010.

ROBERTSON, S. L.; KOMLJENOVIC, J. Non-state actors, and the advance of frontier higher education markets in the global south. Oxford Review of Education, v. 42, n. 5, p. 594-611, 2016.

RUBIÃO, A. História da universidade: Genealogia para um "modelo participativo" 1 ed. Coimbra, Portugal: Centro de Estudos Sociais, Universidade de Coimbra, 2013.

SANDRONI, P. Novíssimo dicionário de economia. São Paulo: Editora Best Seller, 1999.

SANTOS, M. (2013). Por uma outra globalização: do pensamento único à consciência universal. 23 ed. Rio de Janeiro, Brasil: Record, 2013.

SOUSA SANTOS, B. DE. Um discurso sobre as ciências na transição para uma ciência pósmoderna. Estudos Avançados, p. 46-71, 1988.

SOUSA SANTOS, B. DE. Para além do pensamento abissal: das linhas globais a uma ecologia de saberes. In: SOUSA SANTOS, B. DE; MENESES, M. P. (Eds.). . Epistemologias do Sul. 1. ed. São Paulo: Cortez Editora, 2010.

SOUSA SANTOS, B. de. A globalização e as ciências sociais. São Paulo: Cortez Editora, $2011 \mathrm{a}$.

SOUSA SANTOS, B. de. A Universidade no século XXI: Para uma reforma democrática e emancipatória da Universidade. 3. ed. São Paulo: Cortez Editora, 2011 b.

SOUSA SANTOS, B. DE. The end of the cognitive empire: the coming age of epistemologies of the South. 1. ed. Durham: Duke University Press, 2018.

SPIVAK, G. Can the subaltern speak? In: NELSON, C.; GROSSBERG, N. (Eds.), Marxism and the interpretation of culture. p. 271-313. Basingstoke, England: Macmillan, 1988. 
STEIN, S. Internationalization for an uncertain future: tensions, paradoxes, and possibilities. The Review of Higher Education, v. 41, n. 1, p. 3-32, 2017.

STEIN, S.; ANDREOTTI, V. DE O. Cash, competition or charity: international students and the global imaginary. Higher Education, v. 72, n. 2, p. 225-239, 2016.

WALLERSTEIN, I. Impensar a ciência social. São Paulo: Ideias \& Letras, 2006.

WHITSED, C.; GREEN, W. What's in a name? A theoretical exploration of the proliferation of labels for international education across the higher education sector. Journal of Studies in International Education, v. 18, n. 2, p. 105-119, 2014.

VIEIRA, P. A.; VIEIRA, R. de L.; FILOMENO, F. A. O Brasil e o capitalismo histórico. 1 ed. São Paulo: Cultura Acadêmica Editora, 2012.

WALSH, C. Decoloniality in/as Praxis: Openings. In: WALSH, C.; MIGNOLO, W. (Eds.). On decoloniality. Duke University Press, 2018.

YOUNG, R. Postcolonialism: a very short introduction. Oxford, England: Oxford University Press. 2003.

ZAJDA, J. Values education and multiculturalism. In: ZAJDA, J.; HOLGER, D. (Eds.), Global values education. p. 13-23. Dordrecht, Netherlands: Springer, 2009. 